\title{
IMPLEMENTASI DATA MINING UNTUK MENGETAHUI POLA PEMBELIAN OBAT MENGGUNAKAN ALGORITMA APRIORI
}

\author{
Nadya Febrianny Ulfha'), Ruhul Amin ${ }^{2)}$ \\ 1, 2) Jurusan Sistem Informasi STMIK Nusa Mandiri Jakarta, Indonesia \\ Corresponding Author: ruhul.ran@nusamandiri.ac.id
}

\begin{abstract}
Abstrak
Persaingan didunia bisnis menuntut para pengusaha berpikir untuk menemukan suatu cara atau metode untuk meningkatkan transaksi barang yang dijual. Tujuan dari penellitian ini yaitu menyediakan data stok obat yang banyak dibeli oleh pelanggan apotek di Kimia Farma cabang Green Lake Jakarta. Algoritma yang digunakan pada penelitian ini yaitu apriori untuk mengetahui hubungan pola frekuensi penjualan merk obat yang paling sering dibeli pelanggan. Pola asosiasi yang terbentuk dengan minimum support $40 \%$ dan nilai minimum confidence $70 \%$ menghasilkan 17 aturan asosiasi. Strong rules yang didapatkan adalah jika membeli Ponstan 500Mg KPL@100, maka akan membeli Incidal OD 10Mg Cap dengan nilai support 59\% dan nilai confidence $84 \%$. Algoritma apriori dapat digunakan perusahaan untuk menyusun strategi pemasaran dalam memasarkan produk dengan meneliti pola pembelian konsumen.
\end{abstract}

Kata kunci: Algoritma Apriori, Data mining, asosiasi.

\begin{abstract}
Competition in the business world requires entrepreneurs to think of finding a way or method to increase the transaction of goods sold. The purpose of this research is to provide drug stock data that is widely purchased by pharmacy customers at Kimia Farma, Green Lake branch in Jakarta. The algorithm used in this study is a priori to determine the relationship between the frequency of sales of drug brands most frequently purchased by customers. The association pattern formed with a minimum support of $40 \%$ and a minimum value of $70 \%$ confidence produces 17 association rules. The strong rules obtained are that if you buy a 500Mg Ponstan KPL @ 100, you will buy an Incidal OD 10Mg Cap with a support value of 59\% and a confidence value of $84 \%$. A priori algorithm can be used by companies to develop marketing strategies in marketing products by examining consumer purchasing patterns.
\end{abstract}

Keywords: Apriori Algorithm, Data mining, association.

\section{Pendahuluan}

Saat ini data digunakan sebagai landasan untuk mengambil sebuah keputusan penting dan diterapkan pada berbagai bidang mining banyak diaplikasikan diberbagai bidang yaitu bisnis, sains, politik dan lain-lain. Dengan mengetahui pola dari dari data transkasi penjualan melalui data transaksi, dapat diperoleh berbagai informasi tentang kebiasaan para konsumen. contohnya yaitu dapat diketahui item-item apa saja yang sering dibeli secara bersamaan pada satu transaksi. Biasanya produk A dibeli secara bersamaan dengan produk B oleh pelanggan. Itemitem yang sering terbeli secara bersamaan ini disebut asosiasi (association rule) [1]. Association rule merupakan konsep menarik pada data mining untuk menemukan asosiasi atau keterkaitan antar data [2]. Data mining melakukan pengklasifikasian, memprediksi, memperkirakan dan mendapatkan informasi lain yang bermanfaat dari kumpulan data dalam jumlah yang besar [3]. Data mining merupakan proses untuk mendapatkan informasi yang berguna dari gudang basis data yang berupa ilmu pengetahuan. Data mining sering juga disebut knowledge discovery in database $(K D D)$ adalah kegiatan yang meliputi pengumpulan, pemakaian data historis untuk menemukan keteraturan, pola atau hubungan dalam set data berukuran besar [4]. Pola-pola atau rules yang diperoleh nantinya dapat dijadikan acuan dalam menentuan penyusunan letak item secara rapi menurut kombinasi barang yang paling sering dibeli dan saling berhubungan [5] 
Persaingan didunia bisnis menuntut para pengusaha berpikir untuk menemukan suatu cara atau metode untuk meningkatkan transaksi barang yang dijual [6]. Salah satu penerapannya yaitu pada bisnis penjualan obat di apotek. Ketersediaan stok obat merupakan faktor penting dan yang tidak kalah pentingnya adalah mengetahui obat apa saja yang biasa dibeli oleh pelanggan. Ketersediaan stok obat harus selalu dipantau dengan oleh manajemen dan karyawan yang bertugas di apotek. Jika ketersediaan obat tidak terpantau dengan baik maka akan timbul permasalahan yaitu pelanggan akan mencari obat di apotek lain dan ketersediaan stok obat memiliki daya nilai rendah [7].

Algoritma apriori bekerja melakukan pengambilan data dengan aturan asosiatif (Association rule) untuk menentukan hubungan asosiatif suatu kombinasi item [8]. Analisis asosiasi sering disebut juga market basket analysis dikarenakan nnalisis asosiasi sering kali digunakan untuk menganalisis keranjang belanja pelanggan pada suatu supermarket [9]. Penerapan Algoritma Apriori dapat membantu dalam kandidat kombinasi item, kemudian dilakukan pengujian apakah kombinasi tersebut memenuhi parameter support dan confidence minimum yang merupakan nilai ambang yang diberikan oleh pengguna [10]. Jika memenuhi parameter support dan confidence maka hasil tersebut dapat membantu dalam pola pembelian obat dan membantu tata letak obat berdasarkan kecenderungan konsumen membeli obat [11]. Kelebihan asosiasi rule dengan apriori ini adalah lebih sederhana dan dapat menangani data yang besar [12].

Beberapa penelitian lainnya yang menggunakan algoritma apriori untuk analisa data penjualan dan dapat membantu untuk pengembangan strategi pemasaran [13]. Algoritma apriori digunakan untuk menentukan pola pembelian obat dan menghasilkan kecenderungan konsumen membeli obat berdasarkan kombinasi 2 itemset [14]. Penelitian oleh [15] menggunakan algoritma apriori untuk membantu mengetahui pola pembelian produk yang dibeli secara bersamaan.

Tujuan dari penellitian ini yaitu menyediakan data stok obat yang banyak dibeli oleh pelanggan apotek di Kimia Farma cabang Green Lake Jakarta. Dari permasalahan yang disebutkan maka penulis memberikan solusi yaitu menerapkan data mining dengan menggunakan algoritma apriori untuk memprediksi ketersediaan stok obat yang ada di PT. Kimia Farma Apotek cabang Green Lake Jakarta.

\section{Metode Penelitian}

Metodologi penelitian merupakan tahap-tahap penelitian sistematis untuk membantu penelitian menjadi terarah dengan baik. Berikut adalah metodologi penelitian yang dilakukan penulis.

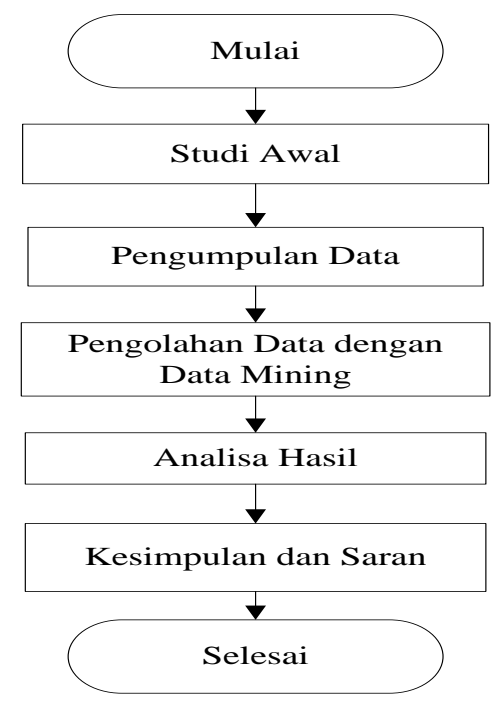

1. Studi Awal

Gambar 1. Tahapan Penelitian

Langkah awal dari penelitian ini adalah dengan mencari dan mempelajari masalah yang ada di PT Kimia Farma Apotek cabang Green Lake Jakarta, kemudian menentukan ruang 
lingkup masalah, latar belakang masalah, dan mempelajari beberapa yang terkait permasalahan dan bagaimana mencari solusi dari masalah tersebut.

2. Pengumpulan Data

Penulis melakukan wawancara, observasi dan dokumentasi di PT Kimia Farma Apotek cabang Green Lake Jakarta. Untuk mengetahui informasi yang dibutuhkan penulis melakukan pengumpulan data penjualan obat periode Agustus 2018 - Oktober 2018 di PT Kimia Farma Apotek cabang Green Lake Jakarta.

3. Pengolahan Data dengan Data Mining

Pada tahap pengolahan data terlebih dahulu melakukan identifikasi masalah yang ada dan sering dihadapi oleh PT Kimia Farma Apotek cabang Green Lake Jakarta, tahap selanjutnya dilakukan analisa masalah yaitu dengan mengumpulkan data penjualan obat selama 3 bulan dengan tujuan agar penulis mengetahui dan memperoleh gambaran yang jelas bagaimana bentuk penyelesaiannya.

4. Analisa Hasil

Penulis melakukan analisis hasil dengan menggunakan Tanagra 1.4 atau aplikasi data mining serta algoritma apriori untuk menghubungkan dengan database yang telah diisi atau data-data yang akan diuji.

5. Kesimpulan

Pada pola perhitungan dengan menggunakan metode algoritma apriori presentase penjualan obat di PT Kimia Farma Apotek akan menunjukkan hasil akhir yaitu dua variabel item set yaitu nilai support dan confidence dengan menggunakan persamaan 1:

$$
\operatorname{Support}(A)=\frac{\text { Jumlah } \text { Transaksi mengandung A }}{\text { Total } \text { Transaksi }} \times 100
$$

\section{Hasil dan Pembahasan}

\subsection{Perhitungan algoritma Apriori}

Data penjualan selama ini tidak tersusun dengan baik, sehingga data penjualan selama ini tidak dimanfaatkan dengan baik oleh perusahaan. Data tersebut hanya disimpan sebagai arsip atau pembukuan perusahaan dan tidak diketahui apa manfaat dari data-data yang ada. Adapun daftar produk obat yang ada di apotek ditampilkan pada Tabel 1.

Tabel 1. Daftar Produk Obat

\begin{tabular}{ll}
\hline No & Nama Obat \\
\hline 1 & Alergine \\
\hline 2 & Amlodipine 5 Mgstrip \\
\hline 3 & Cataflam 50Mg \\
\hline 4 & Dulcolax 5Mg @200TAB \\
\hline 5 & FG Troches @300TAB \\
\hline 6 & Medrol 4Mg \\
\hline 7 & New Diatab TAB \\
\hline 8 & Panadol Cold\&Flu \\
\hline 9 & Lameson 4Mg TAB @100 \\
\hline 10 & Medixon 4Mg \\
\hline 11 & Cefixim 100Mg Capsul \\
\hline 12 & Imboost Force TAB \\
\hline 13 & Incidal OD 10Mg Cap
\end{tabular}




\section{Kimoxil 500Mg Caps \\ 15 Ponstan 500Mg KPL@100}

Data penjualan yang di pilih merupakan data penjualan obat pada PT Kimia Farma Apotek selama 3 bulan, dimulai dari Agustus 2018 sampai Oktober 2018 ditampilkan pada Tabel 2.

Tabel 2. Data Penjualan Obat pada Bulan Agustus - Oktober 2018

\begin{tabular}{lllll}
\hline No & Nama Obat & Agustus & September & Oktober \\
\hline 1. & Alergine & 196 & 244 & 386 \\
\hline 2. & Amlodipine 5 Mgstrip & 505 & 690 & 820 \\
\hline 3. & Cataflam 50Mg & 645 & 546 & 497 \\
\hline 4. & Dulcolax 5Mg @200TAB & 230 & 150 & 224 \\
\hline 5. & FG Troches @300TAB & 220 & 555 & 420 \\
\hline 6. & Medrol 4Mg & 536 & 317 & 344 \\
\hline 7. & New Diatab TAB & 288 & 252 & 99 \\
\hline 8. & Panadol Cold\&Flu & 400 & 490 & 380 \\
\hline 10 & Medixon 4Mg & 180 & 278 & 231 \\
\hline 11. & Cefixim 100Mg Capsul & 95 & 105 & 143 \\
\hline 12. & Imboost Force TAB & 375 & 80 & 112 \\
\hline 13. & Incidal OD 10Mg Cap & 470 & 421 & 359 \\
\hline 14. & Kimoxil 500Mg Caps & 436 & 355 & 320 \\
\hline 15. & Ponstan 500Mg KPL@100 & 366 & 467 & 215 \\
\hline
\end{tabular}

Proses pembentukan $C_{1}$ atau disebut dengan 1 itemset dengan jumlah minimum support $=40 \%$. Dengan menggunakan persamaan 1. Berikut ini adalah penyelesaian berdasarkan data yang sudah ditampilkan pada tabel 2. Proses pembentukan $C_{1}$ atau disebut dengan 1 itemset didapat berdasarkan rumus diatas analisa pola frekuensi tinggi.

$S($ Imboost $)=\frac{\sum \text { Transaksi Imboost }}{92}=\frac{55}{92} \times 100=59,78$

$S($ Incidal $)=\frac{\sum \text { Transaksi Incidal }}{92}=\frac{70}{92} \times 100=76,08$

$S($ Ponstan $500 \mathrm{Mg})=\frac{\sum \text { Transaksi Ponstan }}{92}=\frac{64}{92} \times 100=69,56$

Proses pembentukan $\mathrm{C}_{2}$ atau disebut dengan 2 itemset dengan jumlah minimum support $=40 \%$. Dapat diselesaikan dengan rumus sebagai berikut:

$$
\operatorname{Support}(A, B)=P(A \cap B)=\frac{\text { Jumlah } \text { Transaksi untuk } A \text { dan } B}{\text { Total } \text { Transaksi }} \times 100
$$

Berikut merupakan perhitungan pembentukan $\mathrm{C}_{2}$ atau 2 itemset:

$$
\text { Support (Cataflam 50Mg, Incidal 0D1Mg Cap) }=\frac{60}{92} \times 100=65,2
$$

Proses pembentukan $\mathrm{C}_{3}$ atau disebut dengan 3 itemset dengan jumlah minimum support $40 \%$. Dapat diselesaikan dengan rumus sebagai berikut :

$$
\operatorname{Support}(A, B, \operatorname{dan} C)=\frac{\text { Jumlah } \text { Transaksi untuk } A, B \text { dan } C}{\text { Total Transaksi }} \times 100
$$


Berikut merupakan pembentukan $\mathrm{C}_{3}$ atau 3 itemset minimum Support $40 \%$ :

Support(Ponstan 500Mg KPL@100 0D 10Mg Cap,Cataflam 50Mg) $=\frac{45}{92} \times 100=48,3$

Support(Medro 5Mg, Incidal OD 10Mg Cap,Cataflam 50Mg) $=\frac{44}{92} \times 100=47,8$

Setelah semua pola frekuensi tinggi ditemukan, baru dicari aturan asosiasi yang memenuhi syarat minimum Confidence dengan menghitung Confidence aturan asosiatif $A \rightarrow B$.

Minimal Confidence $=70 \%$

Nilai Confidence dari aturan $\mathrm{A} \rightarrow \mathrm{B}$ diperoleh dengan rumus sebagai berikut:

$$
\text { Confidence }=P(A \mid B)=\frac{\sum \text { Transaksi mengandung } A \text { dan } B}{\sum \text { Transaksi mengandung } A} \times 100
$$

Maka yang memenuhi minimal Support $40 \%$ dan minimal Confidence $70 \%$ dapat dilihat pada Tabel 3.

Tabel 3. Aturan Asosiasi Final

\begin{tabular}{|c|c|c|}
\hline Aturan & Support & Confidence \\
\hline $\begin{array}{l}\text { Jika membeli Imboost Force TAB, maka akan } \\
\text { membeli Ponstan 500Mg KPL@100 }\end{array}$ & $49 \%$ & $82 \%$ \\
\hline $\begin{array}{l}\text { Jika membeli Ponstan 500Mg KPL@100, maka akan } \\
\text { membeli Imboost Force TAB }\end{array}$ & $49 \%$ & $70 \%$ \\
\hline $\begin{array}{l}\text { Jika membeli Lameson 4Mg TAB@100, maka akan } \\
\text { membeli Medrol 4Mg }\end{array}$ & $47 \%$ & $84 \%$ \\
\hline $\begin{array}{l}\text { Jika membeli Imboost Force TAB, maka akan } \\
\text { membeli Incidal OD 10Mg Cap }\end{array}$ & $51 \%$ & $85 \%$ \\
\hline $\begin{array}{l}\text { Jika membeli FG Troches @300TAB, maka akan } \\
\text { membeli Ponstan 500Mg KPL@100 }\end{array}$ & $42 \%$ & $78 \%$ \\
\hline $\begin{array}{l}\text { Jika membeli Kimoxil 500Mg Caps, maka akan } \\
\text { membeli Medrol 4Mg }\end{array}$ & $46 \%$ & $82 \%$ \\
\hline $\begin{array}{l}\text { Jika membeli Ponstan 500Mg KPL@100, maka akan } \\
\text { membeli Incidal OD 10Mg Cap }\end{array}$ & $59 \%$ & $84 \%$ \\
\hline $\begin{array}{l}\text { Jika membeli Incidal OD 10Mg Cap, maka akan } \\
\text { membeli Ponstan 500Mg KPL@100 }\end{array}$ & $59 \%$ & $77 \%$ \\
\hline $\begin{array}{l}\text { Jika membeli Incidal OD 10Mg Cap dan Ponstan } \\
\text { 500Mg KPL@100, maka akan membeli Imboost } \\
\text { Force TAB }\end{array}$ & $41 \%$ & $70 \%$ \\
\hline $\begin{array}{l}\text { Jika membeli Incidal OD 10Mg Cap dan Imboost } \\
\text { Force TAB, maka akan membeli Ponstan 500Mg } \\
\text { KPL@100 }\end{array}$ & $41 \%$ & $81 \%$ \\
\hline $\begin{array}{l}\text { Jika membeli Incidal OD 10Mg Cap dan Amlodipine } 5 \\
\text { Mgstrip, maka akan membeli Ponstan 500Mg } \\
\text { KPL@100 }\end{array}$ & $41 \%$ & $79 \%$ \\
\hline $\begin{array}{l}\text { Jika membeli Ponstan 500Mg KPL@100 dan } \\
\text { Amlodipine } 5 \text { Mgstrip, maka akan membeli Incidal OD } \\
\text { 10Mg Cap }\end{array}$ & $41 \%$ & $86 \%$ \\
\hline $\begin{array}{l}\text { Jika membeli Cataflam 50Mg dan Ponstan } 500 \mathrm{Mg} \\
\text { KPL@100, maka akan membeli Amlodipine } 5 \text { Mgstrip }\end{array}$ & $41 \%$ & $72 \%$ \\
\hline
\end{tabular}




\begin{tabular}{lll}
\hline Aturan & Support & Confidence \\
\hline Jika membeli Cataflam 50Mg dan Ponstan 500Mg & $49 \%$ & $85 \%$ \\
KPL@100, maka akan membeli Incidal OD 10Mg Cap & \\
& \\
\hline $\begin{array}{l}\text { Jika membeli Ponstan 500Mg KPL@100 dan Imboost } \\
\text { Force TAB, maka akan membeli Incidal OD 10Mg Cap }\end{array}$ & \\
& \\
\hline Jika membeli Cataflam 50Mg dan Imboost Force TAB, & $41 \%$ & $84 \%$ \\
maka akan membeli Incidal OD 10Mg Cap & \\
& \\
\hline $\begin{array}{l}\text { Jika membeli Cataflam 50Mg dan Amlodipine 5 } \\
\text { Mgstrip, maka akan membeli Incidal OD 10Mg Cap }\end{array}$ & \\
\end{tabular}
Mgstrip, maka akan membeli Incidal OD 10Mg Cap

\section{Kesimpulan}

Dari hasil analisa dan pembahasan didapat kesimpulan : Pertama data mining sangat berguna untuk mengetahui hubungan pola frekuensi penjualan merk obat yang paling sering dibeli konsumen. Kedua, algoritma apriori dapat digunakan perusahaan untuk menyusun strategi pemasaran dalam memasarkan produk dengan meneliti pola pembelian konsumen. Ketiga, dengan metode algoritma apriori dapat disimpulkan bahwa nama-nama obat yang paling banyak terjual dengan minimum support $40 \%$ adalah Alergine, Amlodipine 5Mgstrip, Cataflam 50Mg, FG Troches @300TAB, Medrol 4Mg, New Diatab TAB, Panadol Cold\&Flu, Lameson 4Mg TAB@100, Imboost Force TAB, Incidal OD 10Mg Cap, Kimoxil 500Mg Caps, Ponstan 500 Mg KPL@100. Terakhir, pola asosiasi yang terbentuk dengan minimum support $40 \%$ dan nilai minimum confidence $70 \%$ menghasilkan 17 aturan asosiasi. Strong rules yang didapatkan adalah jika membeli Ponstan 500Mg KPL@100, maka akan membeli Incidal OD 10Mg Cap dengan nilai support $59 \%$ dan nilai confidence $84 \%$.

\section{References}

[1] H. Hutahaean, B. Sinaga, and A. Rajagukguk, "ANALISA DAN PERANCANGAN APLIKASI ALGORITMA APRIORI UNTUK KORELASI PENJUALAN PRODUK ( STUDI KASUS : APOTIK DIORY FARMA )," vol. 1, no. 1, pp. 7-13, 2016.

[2] H. Widayu, S. Darma, N. Silalahi, and Mesran, "DATA MINING UNTUK MEMPREDIKSI JENIS TRANSAKSI NASABAH PADA KOPERASI SIMPAN PINJAM DENGAN ALGORITMA C4.5," vol. 1, no. 2, pp. 32-37, 2017.

[3] Y. Mardi, "Data Mining : Klasifikasi Menggunakan Algoritma C4.5," EdikInformatika, vol. 2, no. 2, 2016.

[4] S. J. Tamba and E. Bu'ulolo, "IMPLEMENTASI ALGORITMA APRIORI PADA SISTEM PERSEDIAAN BUAH-BUAHAN (STUDI KASUS : LOTTE MART WHOLESALE MEDAN)," Oct. 2019.

[5] A. Masnur, "Analisa Data Mining Menggunakan Market Basket Analysis untuk Mengetahui Pola Beli Konsumen," SATIN-Sains dan Teknol. Inf., vol. 1, no. 2, pp. 32-40, 2015.

[6] K. Tampubolon, H. Saragih, and B. Reza, "IMPLEMENTASI DATA MINING ALGORITMA APRIORI PADA SISTEM PERSEDIAAN ALAT-ALAT KESEHATAN," Proc. Prehist. Soc., vol. 32, pp. 73-85, 2013.

[7] Sugiyantno and A. P. Widyasari, "APLIKASI MONITORING KETERSEDIAAN STOK BARANG MINIMARKET DENGAN METODE MARKET BASKET ANALYSIS ( MBA )," in Seminar Nasional Teknologi Informasi dan Multimedia 2016, 2016, pp. 6-7.

[8] Kusrini and E. Taufiq, Algoritma Data Mining. Andi Yogyakarta, 2009. 
[9] N. F. Fahrudin, "Penerapan Algoritma Apriori untuk Market Basket Analysis," MINN J., vol. 4, no. 1, 2019.

[10] S. Nurajizah, "Analisa Transaksi Penjualan Obat menggunakan Algoritma Apriori," INOVTEK Polbeng - Seri Inform., vol. 4, no. 1, p. 35, 2019.

[11] R. Yanto and R. Khoiriah, "Implementasi Data Mining dengan Metode Algoritma Apriori dalam Menentukan Pola Pembelian Obat,” pp. 102-113, 2015.

[12] M. Fauzy, K. R. S. W, and I. Asror, "PENERAPAN METODE ASSOCIATION RULE MENGGUNAKAN ALGORITMA APRIORI PADA SIMULASI PREDIKSI HUJAN WILAYAH KOTA BANDUNG," Utama, vol. 2, no. 2, 2016.

[13] M. Badrul, "Algoritma Asosiasi Dengan Algoritma Apriori Untuk Analisa Data Penjualan," None, vol. 12, no. 2, pp. 121-129, 2016.

[14] M. Safii and A. Trydillah, "Implementasi Data Mining Dalam Menentukan Pola Pembelian," vol. 3, no. 1, pp. 66-71, 2019.

[15] M. P. Tana, F. Marisa, and I. D. Wijaya, "Penerapan Metode Data Mining Market Basket Analysis Terhadap Data Penjualan Produk Pada Toko Oase Menggunakan Algoritma Apriori," J I M P - J. Inform. Merdeka Pasuruan, vol. 3, no. 2, Aug. 2018. 